\title{
Kreditsicherheiten an beweglichen Sachen und Forderungen
}

Eine materiell-, insolvenz- und kollisionsrechtliche Studie des Rechts der Mobiliarsicherheiten vor dem Hintergrund internationaler und europäischer Entwicklungen

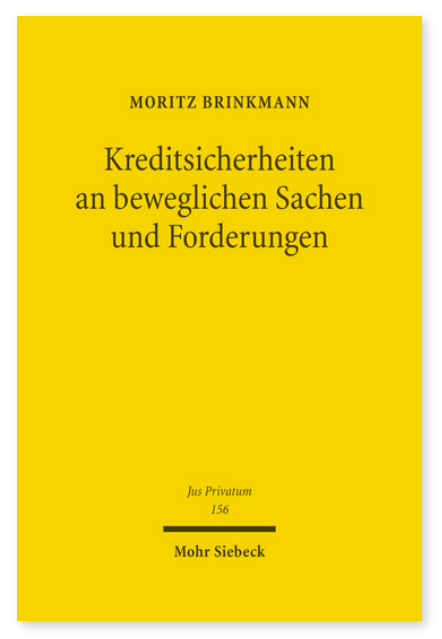

2011. XXV, 555 Seiten. JusPriv 156

ISBN 978-3-16-151233-9

DOI 10.1628/978-3-16-151233-9

eBook PDF 149,00€

ISBN 978-3-16-150379-5

Leinen $149,00 €$
Kreditsicherheiten an beweglichen Sachen und Forderungen sind von wesentlicher Bedeutung für die Versorgung eines Unternehmens mit Fremdkapital. Ihr Wert zeigt sich insbesondere in der Insolvenz des Sicherungsgebers. Moritz Brinkmann analysiert die materiell- und haftungsrechtlichen Voraussetzungen der insolvenzrechtlichen Anerkennung von Mobiliarsicherheiten. Er weist nach, dass insbesondere für revolvierende Globalsicherheiten ein haftungsrechtliches Legitimationsdefizit besteht, das von der Rechtsprechung durch die Anwendung von § 138 Abs. 1 BGB und des Insolvenzanfechtungsrechts korrigiert wird. Der Autor arbeitet die sich hieraus ergebenden materiell-, insolvenz- und kollisionsrechtlichen Unsicherheiten für die Parteien eines Sicherungsgeschäfts heraus und stellt dem deutschen Recht andere Regelungsmodelle - u.a. Article 9 UCC und Book IX des DCFR - für ein künftiges Mobiliarsicherungsrecht gegenüber.

Moritz Brinkmann Geboren 1972; Studium der Rechtswissenschaft in Hamburg und Heidelberg; 2002 Promotion; 2002/03 Masterstudium an der McGill Universität, Montreal; 2009 Habilitation; seit 2010 Professor für Bürgerliches Recht, deutsches und europäisches Zivilverfahrensrecht sowie Insolvenzrecht an der Universität Bonn.

Jetzt bestellen:

https://mohrsiebeck.com/buch/kreditsicherheiten-an-beweglichen-sachen-und-forderungen-9783161512339?no_cache=1 order@mohrsiebeck.com

Telefon: +49 (0)7071-923-17

Telefax: +49 (0)7071-51104 